\title{
Cerebral air embolism: a rare complication following balloon dilation
}

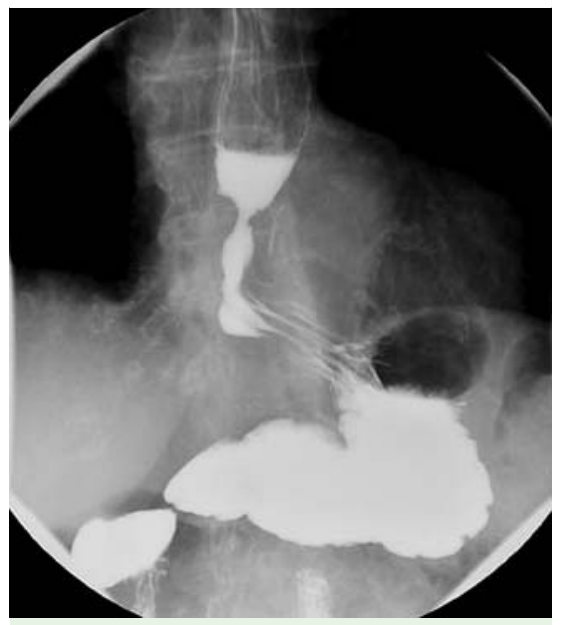

Fig. 1 Barium swallow demonstrating short stricture in an 84-year-old woman with a 12-month history of dysphagia and reflux symptoms.

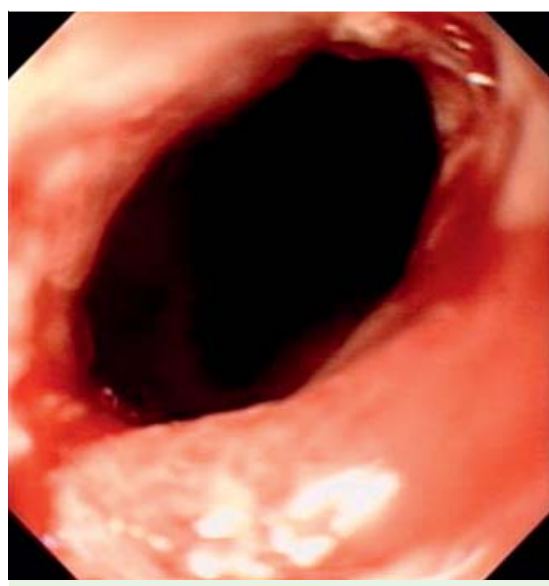

Fig. 3 Initial gastroscopy after endoscope passage.

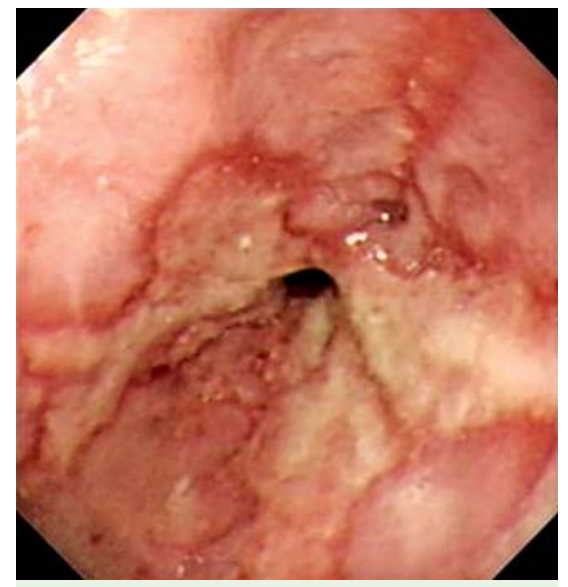

Fig. 2 Initial gastroscopy showing stricture.

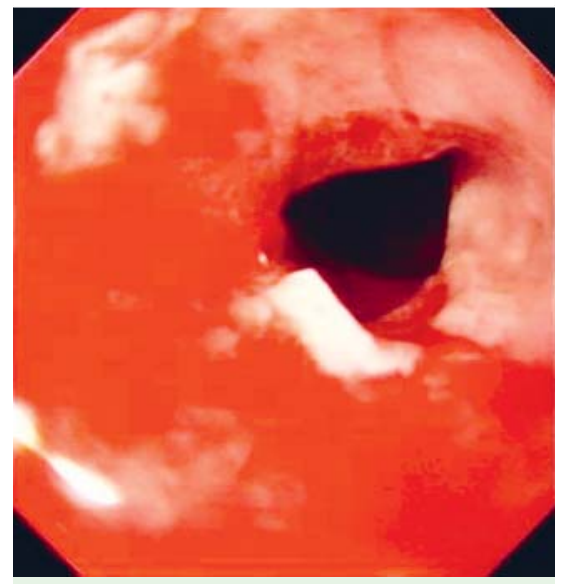

Fig. 4 Second gastroscopy post dilation.

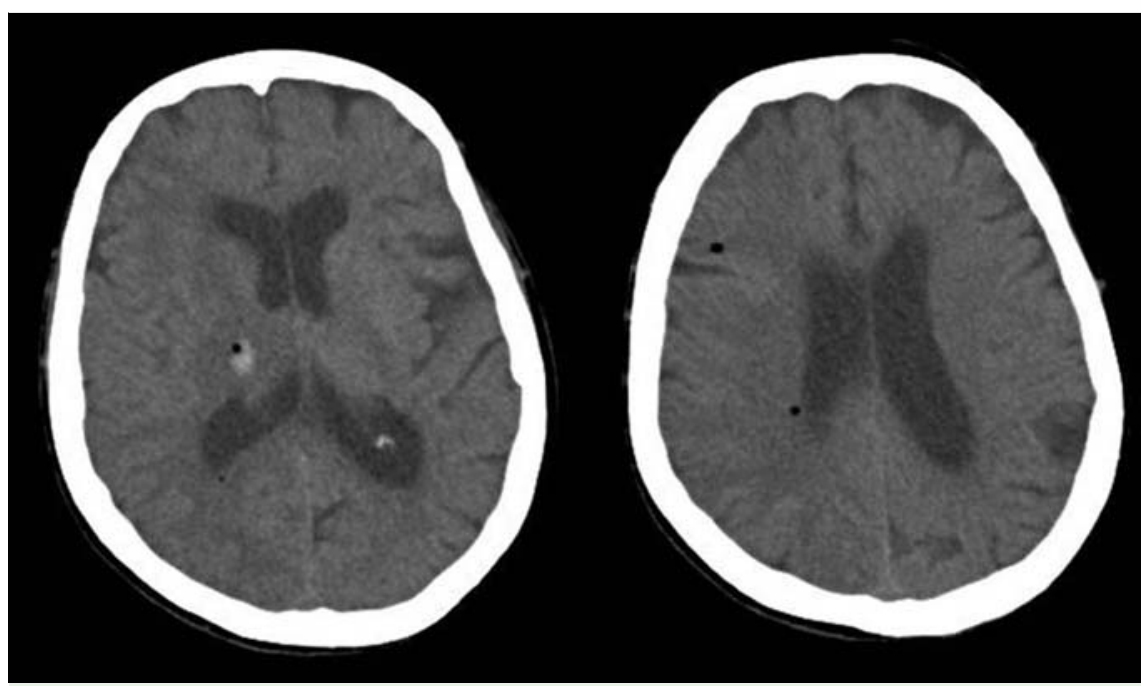

Fig. 5 Pockets of air in the right cerebral hemisphere, with slight hemorrhage in the basal ganglia.
Balloon dilation is an established treatment for benign esophageal strictures [1]. We report a rare case of pneumoencephalus secondary to balloon dilation of a peptic stricture.

An 84-year-old woman was referred with a year-long history of dysphagia and reflux symptoms. Barium swallow showed a 2-cm stricture in the distal third of the esophagus ( Fig.1). Initial gastroscopy revealed esophagitis and stricture above a 4-cm hiatus hernia, which was traversable with the gastroscope ( $\bullet$ Fig. 2 ). The stricture was dilated with the passage of the gastroscope ( Fig.3) and multiple biopsy samples were taken, which were benign. At repeat procedure 6 weeks later, the stricture was still present but not traversable. As the patient was dysphagic, the stricture was dilated with a "through the scope" CRE fixed wire esophageal balloon dilation catheter (Boston Scientific, Natick, Massachusetts, USA) to $15 \mathrm{~mm}$. A small linear tear was noted above the balloon ( $\bullet$ Fig.4) after the procedure, and $20 \mathrm{~mL}$ 1:10000 epinephrine was injected and four Resolution clips (Boston Scientific) were placed to achieve hemostasis. The patient became less responsive immediately following the procedure and was transferred to the intensive care unit, where she was intubated and ventilated. Computed tomography (CT) revealed small pockets of gas in the right cerebral hemisphere ( Fig.5). The patient was transferred to another hospital for hyperbaric oxygen therapy but sadly passed away the next day.

There have been several reports of pneumoencephalus after upper gastrointestinal endoscopy, a few of which occurred after dilation $[2,3]$. Although the cause of this complication is unclear, it is thought to be related to insufflation causing air to enter the vascular system through the disrupted mucosa. Cerebral air embolism can occur if air either directly enters the arterial system or is shunted across after entering the venous system [4]. Once pneumoencephalus has occurred, the only treatment option available is supportive management and hyperbaric oxygen therapy [5].

Endoscopy_UCTN_Code_CPL_1AH_2AF

Competing interests: None 


\section{Pee, S. Basu, A. Loganayagam}

Department of Gastroenterology, Queen Elizabeth Hospital Woolwich, United Kingdom

\section{References}

1 Standards of Practice Committee, ASGE. Esophageal dilatation. Gastrointest Endosc 2006; 63: 755-760

2 Green BT, Tendler DA. Cerebral air embolism during upper endoscopy: case report and review. Gastrointest Endosc 2005; 61: 620-623
3 Thackray NM, Murphy PM, Mclean RF et al. Venous air embolism accompanied by echocardiographic evidence of transpulmonary air passage. Crit Care Med 1996; 24: 359361

4 Leach RM, Rees PJ, Wilmshurst P. Hyperbaric oxygen therapy. BMJ 1998; 317: 1140

5 Blanc P, Boussuges A, Henriette $K$ et al. Iatrogenic cerebral air embolism: importance of an early hyperbaric oxygenation. Intensive Care Med 2002; 28: 559

\section{Bibliography}

DoI http://dx.doi.org/

10.1055/s-0032-1326251

Endoscopy 2013; 45: E93-E94

(c) Georg Thieme Verlag KG

Stuttgart · New York

ISSN 0013-726X

\section{Corresponding author}

\section{Dr A. Loganayagam}

Department of Gastroenterology Queen Elizabeth Hospital Woolwich London SE18 4QH

United Kingdom

a.loganayagam@nhs.net 